\title{
Matrix-Assisted Laser Desorption Ionization Time-of-Flight Mass Spectrometry of Underivatized and Permethylated Gangliosides
}

\author{
Peter Juhasz and Catherine E. Costello \\ Department of Chemistry, Massachusetts Institute of Technology, Cambridge, Massachusetts, USA
}

\begin{abstract}
Underivatized and permethylated gangliosides have been studied by the matrix-assisted laser desorption (MALD) ionization technique. The samples investigated included commercially available and highly purified gangliosides from the human brain containing up to five sialic acid residues. Several permethylated gangliosides have also been studied, and MALD has proven successful in analyzing multicomponent mixtures of glycolipids with different fatty acyl residues. During the studies a variety of matrix and wavelength combinations have been tested in both the positive and negative ion modes. The best results have been obtained with the matrices 2,5-dihydroxybenzoic acid, 4-hydrazinobenzoic acid, 1,5-diaminonaphthalene, and 6-aza-2-thiothymine. Negative ion mass spectra of the underivatized gangliosides have always been of better quality than the positive ion mass spectra, exhibiting better signal-to-noise ratio, better resolution, less fragmentation, and less adduct formation with $\mathrm{Na}^{+}$and $\mathrm{K}^{+}$. With increasing number of sialic acid substituents the molecular ion region became less and less resolvable, leading to broadened peaks even in the negative ion mode. Fragmentation could frequently be observed in the negative ion mode, and it was pronounced in the positive ion mode. The major fragmentation pathways corresponded to loss of sialyl group(s) and to decarboxylation of one of the sialyl residues. For underivatized gangliosides the typical sample amount used was 10-20 pmol. Permethylation led to a significant improvement in sensitivity (two orders of magnitude); the detection limit of permethylated gangliosides was about $10 \mathrm{fmol}$. The higher stability of the permethylated compounds was indicated by the fact that positive ion mass spectra exhibited only a marginal extent of fragmentation. (I Am Soc Mass Spectrom 1992, 3, 785-796)
\end{abstract}

$O$ ince the introduction of matrix-assisted laser desorption (MALD) ionization by Karas et al. [1] and Tanaka et al. [2], numerous studies have demonstrated the huge potential of this technique. It can produce intact molecular ions from proteins with

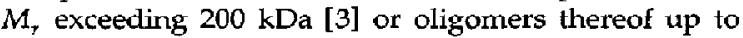
$500 \mathrm{kDa}[4]$, or in special cases from proteins consisting of noncovalently bound subunits [3]. The molecular weights of heavily glycosylated proteins that confound even approximate mass measurement with sodium dodecylsulfate (SDS)-polyacrylamide gel electrophoresis (PAGE) and also pose a serious challenge to electrospray ionization mass spectrometry have been determined by MALD ionization [5, 6]. In addition to proteins and pepticles, other classes of macromolecules such as oligosaccharides [7], oligonucleotides up to 40 $\mathrm{kDa}$ [8], and even polymers [9] have been shown to be amenable to this technique. MALD ionization can be used for direct analysis of complex mixtures such as

Address reprint requests to Catherine E. Costello, Department of Chemistry, Room 56-029, Massachusetts Institute of Technology, Cambridge, MA 02139 enzymatic digests [10] without requiring any purification of the reaction mixture. In general, there is no need for specific sample preparation (such as derivatization in order to improve sensitivity), the ionization process apparently being quite insensitive to most impurities.

The MALD ionization technique can be coupled with various types of mass analyzers. Time-of-flight (TOF) mass analyzers are ideally suited for MALD ionization, because sensitivity and speed of the analysis are very high and the analyzer itself has no upper limit for the mass of transmitted ions. For readily ionizable samples (e.g., smaller proteins and peptides), mass spectra can be obtained even at the low femtomole level [11]. The decrease of sensitivity with increasing mass can be attributed to the decline of detector sensitivity rather than to the loss of sensitivity of the ionization method. Mass accuracy of $0.1-0.2 \%$ for MALD-TOF can be easily maintained; this can be increased to the level of $0.01 \%$ with the use of internal standards [12]. The most serious drawback of the TOF analyzers is their limited mass resolution. This problem can be partly eliminated by employing an ion 
reflectron [13,14], which compensates (up to the second order) for the initial energy spread of the ions. Effects other than energy spread may also contribute to diminished resolution above $10 \mathrm{kDa}$.

MALD ionization has been demonstrated to be compatible with Fourier transform mass spectrometric (FTMS) instruments $[8,15]$ and also with magnetic sector instruments when an array detector is employed [16]. With FTMS the observed sensitivity is considerably lower than for TOF techniques, because of the lower ion transmission. The mass resolution of MALD spectra recorded with FTMS and magnetic sector instruments is substantially better than that of linear TOF analyzers (though not significantly better than that of reflectron TOF analyzers), and they offer the immediate possibility for MS/MS analysis.

The versatility of MALD ionization can be attributed to a number of free parameters of this method that are currently the subject of active research. MALD allows more control over energy deposition into the sample than do other related ionization techniques such as plasma desorption, fast-atom bombardment (FAB), and secondary ionization mass spectrometry (SIMS). Although the laser fluence is easy to vary by means of filters, attenuators, or defocusing, it should be kept close to the ion formation threshold (at least with TOF analyzers), to obtain optimum resolution and minimal extent of metastable decay. On the other hand, the variety of wavelength and matrix combinations and compound class-specific sample preparation methods that are just beginning to be explored provide rich resources of new solutions to problems of biochemical interest. This study was designed to explore some of these features as they relate to gangliosides, a class of compounds of biological significance that has always posed a challenge to mass spectrometric analysis.

Gangliosides are sialic acid ( $N$-acetyl or $N$-glycolylneuraminic acid) containing glycolipids and comprise a class of cell membrane components that play important roles, not yet fully understood, in processes involving communication of the cell with its environment, cell-cell recognition and adhesion, contact inhibition, cell growth and differentiation, and serve as receptors for toxins, hormones, and ions [17-19]. They are particularly abundant in the central nervous system, where they are concentrated at the outer surface of the plasma membrane [20]. Striking qualitative and quantitative changes in ganglioside distributions occur during stages of normal and aberrant development of organisms and organ systems [18] and during oncogenesis [21].

Gangliosides have as common structural features a hydrophobic, membrane-anchored ceramide and an exposed hydrophilic carbohydrate chain containing one or more sialic acid residues at various linkage sites. Within the ceramide, a fatty acyl residue is amidelinked to a long-chain base (LCB), a hydrocarbon substituted with hydroxyl groups on $C-1$ and $C-3$ and the acylated amino group on C-2. A variety of LCBs and fatty acyl groups occur in native gangliosides, differing in their hydrocarbon chain lengths, the number of additional hydroxyl groups, and sites of unsaturation (if any). The most common LCB found in glycolipids is $4 E$-sphingenine, $(2 S, 3 R, 4 E)$-2-amino-4-octadecene1,3-diol, and the general term "sphingoid" bases derives from this name. In the gangliosides of the nervous system, the occurrence of longer LCBs is frequent, and there is usually heterogeneity in the LCB.

Mass spectrometric analysis of intact gangliosides and their derivatives can provide information on their molecular weight distributions and many structural details. Electron ionization of reduced/permethylated derivatives [17] and FAB or liquid SIMS of permethylated derivatives [22-25] have been most widely used. Incorporation of related techniques also has advantages. On-line thin-layer chromatography has been reported for native gangliosides [26] and continuous flow FAB has recently been demonstrated in the 5-250 ng range for underivatized monosialo-gangliosides [27]. Permethylation facilitates separation by supercritical fluid chromatography (SFC) at the nanogram level; direct chemical ionization has been employed for identifications of SFC-purified permethylated gangliosides, but required microgram-level samples [28]. ${ }^{252} \mathrm{Cf}-$ plasma desorption mass spectrometry has only limited suitability for analyses of native gangliosides [29], but has been successfully utilized during the structural determination of some novel permethylated gangliosides [30]. A preliminary report of the application of atmospheric pressure electrospray ionization to ganglioside analysis has been presented [31].

Supplementary information can be obtained by degradation to sugars, LCBs, and fatty acids. Sample requirements for these procedures may be prohibitive, however, and information is lost about the individual components of mixtures. FAB tandem mass spectrometry (MS/MS) offers the advantage that the structures of the individual components of ganglioside mixtures may be determined [32-34]. Sensitivity and information content are improved when permethylated or reduced/permethylated derivatives are analyzed [35]. For larger gangliosides, the sample. requirement is around 1 nmol. While this amount is small compared to that needed for other techniques used for detailed structural studies (such as NMR), it still represents a barrier to rapid screening experiments and the evaluation of gangliosides present at very low (picomole and subpicomole) levels in some tissue extracts.

The high degree of success achieved in the analysis of proteins and peptides by MALD ionization suggests that its application to ganglioside analysis should also be examined. An impressive demonstration of the use of MALD-TOF mass spectrometry for the molecular weight determination of native and permethylated neutral glycosphingolipids has appeared [36]. Chait et al. [37] have initiated studies on underivatized and peracetylated oligosaccharides containing sialic acid residues. We report here the results of an investigation of the MALD-TOF mass spectrometry behavior of a 
series of native gangliosides and their permethylated derivatives under experimental conditions that include variations in both matrix and wavelength.

\section{Experimental}

Experimental investigations were carried out on a VT2000 (Vestec Corp., Houston, TX) TOF mass spectrometer. The original instrument has been augmented with two additional lasers and associated optics, a camera-monitor observation system, and data processing software integrated into the VAX-based environment (Digital Equipment Corp., Maynard, MA) of the laboratory. A detailed description of the instrument and data processing has been presented elsewhere [38].

A nitrogen laser (Laser Science Inc., Newton, MA) radiating at $337 \mathrm{~nm}$ (pulse width $3 \mathrm{~ns}$ ) and the fourth harmonic of a Nd:YAG laser (Lumonics Inc., Ottawa, Ontario) radiating at $266 \mathrm{~nm}$ (pulse width $10 \mathrm{~ns}$ ) were used for desorption. The two laser beams were merged and steered through a variable attenuator (Newport Corp., Fountain Valley, CA), a fused quartz prism, and a quartz objective (25-cm focal length) into the ion source. The sample-matrix mixture was applied to a stainless steel probe tip (2-mm diameter). The sample irradiation was observed by means of a cameramonitor system (Pulnix, Sunnyvale, CA). The intensity of the laser beam was not measured, but almost all the spectra were obtained close to the threshold irradiance for ion formation.

Ions were accelerated to $30 \mathrm{keV}$ in the positive ion mode; this value was reduced to $25 \mathrm{keV}$ in the negative ion mode to avoid high-voltage ion source arcing. lons drifled along the 2-m long flight tube and were detected with a 20-stage secondary electron multiplier (Beckton-Dickinson, Towson, MD). The signal was preamplified and led to a $200-\mathrm{MHz}$ fast digitizer (LeCroy TR8828D, Chestnut Ridge, NY) and to an oscilloscope (Tektronix Inc., Beaverton, OR) for realtime observation. Digitized and averaged data were sent via a general purpose interface box (GPIB) interface to a 386-based personal computer and from there via DECnet (Digital Equipment Corp., Maynard, MA) to one of the VAX workstations in the local area VAXcluster. Data processing software has been developed for the VAXstations in this laboratory, utilizing interactive peak selection and evaluation [38]. From a single sample preparation typically $6-20$ spectra were accumulated, each of them being a sum of 30-50 laser pulses. Calibration of the mass spectra could usually be done without using an internal standard, because the two constants necessary for calibrating TOF mass spectra have always been consistent enough to maintain a mass accuracy better than $0.2 \%$. In the mass range of interest this accuracy corresponded to about 5 $\mathrm{u}$, which was satisfactory to interpret the mass spectra in many cases. When more accurate mass measurements were needed, matrix peaks (as many as possible) were used as internal standards. Mass assignment errors using this method were usually below $1 \mathrm{u}$.

Matrices, all purchased from Aldrich Chemical Co. (Milwaukee, WI) included sinapinic acid (3,5-dimethoxy-4-hydroxycinnamic acid), 2,5-dihydroxybenzoic acid, 6-aza-2-thiothymine, 1,5-diaminonaphthalene, 4hydrazinobenzoic acid, and 2-thiohydantoin. Gangliosides $G_{M l a}, G_{D l a}, G_{D 1 b}$ and $G_{T 1 b}$ were purchased from Boehringer Mannheim (Indianpolis, IN) and were permethylated using the procedure of Ciucano and Kerek [39], as modified by Gunnarsson [40]. Highly purified samples of the native gangliosides $G_{D 1 b}, G_{T 1 b}, G_{\mathrm{Q} 1 b}$, $G_{P 1}$ (a mixture of $G_{P 1 b}$ and $G_{P 1 c}$ ), and the permethylated derivatives of $G_{D 1 b}$ and $G_{T 1 b}$ were provided by J.-E. Månsson and L. Svennerholm (Göteborg University, Sweden). The structures of the ganglioside standards were verified by FAB-MS and MS/MS prior to their use in this study. A mixture of gangliosides expressed by rat dorsal root ganglion neurons had been obtained earlier from D. K. Chou and F. B. Jungalwala (Eunice Kennedy Shriver Center, Waltham, MA) and had been characterized by negative ion FABMS [41]. Details of solution preparation for samples and matrices are discussed in the following section.

\section{Results and Discussion}

\section{Gangliosides}

Gangliosides are named through the text, tables, and figures using the systematic $G_{X n}$ symbols introduced by Svennerholm [42], in which $X=M, D, T, Q, P$ indicates the number (1-5) of sialic acid residues, and the $n$ following the letter refer to the relative TLC migration positions of isomers. The generic structure of the gangliosides investigated is shown:

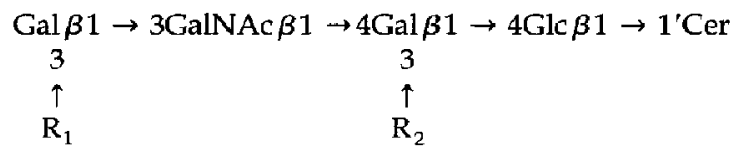

Individual structures of the underivatized gangliosides involved in this sludy are given in Table 1 , where the corresponding (isotope averaged) molecular weights are also listed. (For the gangliosides in Table 1, names according to the חUPAC-proposed nomenclature [43] are provided in the footnote. ${ }^{1}$ ) All the samples listed in Table 1 were inhomogeneous in the LCB. With the

\footnotetext{
${ }^{1}$ In the IUPAC-proposed abbreviations [43], series names depend on structures and biogenetic relationships and include linkage information. For example, ganglio indicates GalNAc $\beta 1 \rightarrow 1 G a l \beta 1 \rightarrow 1 G l c \beta 1$ $\rightarrow$ 1'Cer; Gg ${ }_{4} \mathrm{Cer}=\mathrm{GgOse}_{4} \mathrm{Cer}=\mathrm{Gal} \beta 1 \rightarrow 3 \mathrm{GalNAc} \beta 1 \rightarrow 4 \mathrm{Gal} \beta 1$ $\rightarrow 4 \mathrm{Glc} \beta 1 \rightarrow 1^{\prime}$ Cer. The subsctipt refers to the number of "root sugars": Roman numerals I- IV designate root sugars counting from the ceramide end; a superscript Arabic numeral indicates the attachment site on the root sugar residue. The IUPAC abbreviations for the gangliosides discussed are the following: $\mathrm{G}_{\mathrm{M} 1}, \Pi^{3} \mathrm{NeuAc}-\mathrm{GgOse}_{4} \mathrm{Cer}$; $\mathrm{G}_{\mathrm{DJa}} \mathrm{IV}^{3} \mathrm{NeuACII}^{3} \mathrm{NeuAC}-\mathrm{GgOse}_{4} \mathrm{Cer} ; \mathrm{G}_{\mathrm{DV}}$, II ${ }^{3}$ (NeuAc) -GgOse $_{4} \mathrm{Cer}^{3}$

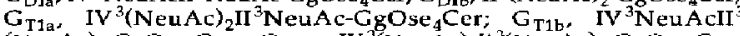

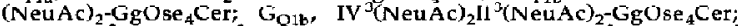
Golb IV ${ }^{3}$ (NeuAC) ${ }_{2} I^{3}$ (NeuAc) ${ }_{2}$ GgOse $_{4}$ Cer; $G_{\text {Plu }}$ IV $^{3}$ (NeuAC) ${ }_{3} I^{3}$ $(\mathrm{NeuAc})_{2}-\mathrm{CgOse}_{4} \mathrm{Cer} \mathrm{C}_{\mathrm{P} 1 \mathrm{c}}$ IV $\mathrm{IV}^{3}(\mathrm{NeuAc})_{2} \mathrm{II}^{3}(\mathrm{NeuAc})_{3}-\mathrm{GgOse}_{4} \mathrm{Cer}$.
} 
Table 1. Ganglioside standards investigated by matrix-assisted laser desorption ionization time-of-flight mass spectrometry

\begin{tabular}{|c|c|c|c|}
\hline & $R_{1}$ & $\mathbf{R}_{2}$ & $\begin{array}{c}M_{r} \\
\left(M_{1} / M_{2}\right)\end{array}$ \\
\hline$G_{M 1 a}$ & Neu5Ac $\alpha 2$ & $\mathbf{H}$ & $\begin{array}{c}1546.8,1574.9 \\
(1 / 1)\end{array}$ \\
\hline $\mathrm{G}_{\mathrm{D} 1 \mathrm{a}}$ & Neu5Acc 2 & Neu5Ac $\alpha 2$ & $\begin{array}{c}1838.1,1866.1 \\
(1 / 2)\end{array}$ \\
\hline$G_{D \text { 1 }}$ & $\mathbf{H}$ & Netu5Ac $\alpha 2-8$ Neu5Aci $\alpha 2$ & $\begin{array}{c}1838.1,1866.1 \\
(1 / 2)\end{array}$ \\
\hline $\mathrm{G}_{\mathrm{T} 1 \mathrm{~b}}$ & Neu5Ac $\propto 2$ & Neu5Ac $\alpha 2-8$ Neu $5 A c \alpha 2$ & $\begin{array}{c}2129.4,2157.4 \\
(2 / 5)\end{array}$ \\
\hline $\mathrm{G}_{Q 1 \mathrm{~b}}$ & Neu5Ac $\alpha 2-8$ Neu5Ac $\alpha 2$ & Neu $5 A c \alpha 2-8$ Neu 5 Ac $\alpha 2-$ & $\begin{array}{c}2420.6,2448.7 \\
(3 / 2)\end{array}$ \\
\hline $\mathrm{G}_{\mathrm{P} 1 \mathrm{~b}}$ & Neu5Ac $\alpha 2-8$ Neu5Ac $\alpha 2-8$ Neu5Ac $\alpha 2-$ & Neu5Ac $\alpha 2-8$ Neu 5 Ac $\alpha 2-$ & $2711.9,2739.9$ \\
\hline $\mathrm{G}_{\mathrm{P} 1 \mathrm{c}}$ & Neu5Ac $\alpha 2-8$ Neu5Ac $\alpha 2$ & Neu5Ac $\alpha 2-8$ Neu5Ac $\alpha 2-8$ Neu5Ac $\alpha 2$ & $(2 / 1)$ \\
\hline
\end{tabular}

usual notation of the sphingoid bases [18] the two major components differing by two methylene groups corresponded to d18:1 and d20:1. Heterogeneity in the fatty acyl group is also common for native gangliosides but in these cases the samples contained $N$ stearoyl almost exclusively. The relative abundances are indicaled for the major molecular species (Table 1). based on FAB-MS determinations of resolved molecular ions and ceramide fragment ions (the term molecular ion will be used for $[\mathrm{M}+\mathrm{H}]^{+}$and $[\mathrm{M}-\mathrm{H}]^{-}$ions).

In addition to the underivatized gangliosides shown in Table 1, the permethylated derivatives of $G_{\text {vib }}$ and $\mathrm{G}_{\mathrm{T} 1 \mathrm{~b}}$ were subjected to MALD-TOF mass spectrometry. Permethylation converts all the hydroxyl groups to methoxyl groups, and the $\mathrm{NH}$ in both the LCB and the $N$-acetyl groups to $N$-methyl. The molecular weights of the two homologs of these compounds thus shifted to $2188.8,2216.8 \mathrm{Da}$ and $2550.2,2578.2 \mathrm{Da}$, respectively. During the evaluation of the mass spectra minor components corresponding to undermethylation were detected.

\section{Matrices}

It has been observed that in the low mass range (below $5 \mathrm{kDa})$ MALD spectra can exhibit matrix-specific features [38]. In urder to accumulate more experience we investigated a number of novel matrices, as well as those now in routine use. The structures and UVwavelength utility of the matrices investigated are shown in Figure 1. Since the known matrices have been found by testing organic compounds having desirable physical features, such as absurption coefficienl at the chosen laser wavelength, vacuum stability, solubility, etc., primarily on standard peptides and proteins (insulins, cytochrome $c$, myoglobins) in the positive ion mode, it seemed reasonable to consider also matrices that may not be suitable for proteins but might give favorable results with gangliosides, and to carry out the experiments in the negative ion mode as well. Doing so, a few more compounds have been found to be useful as matrices for gangliosides.

Although a variety of malrices have now been described in the literature, two of them are most widely used for UV-MALD of proteins and peptides. Sinapinic acid (SA) (3,5-dinethoxy-4-hydroxycirnamic acid), introduced by Beavis and Chait [44], is useful at the frequency of both the $N_{2}$ laser $(337 \mathrm{~nm}$ ) and the frequency quadrupled $\mathrm{Nd} Y \mathrm{YAG}$ laser (266 nm). 2,5Dihydroxybenzoic acid (DHB), the matrix preferred by the Münster group [11], can be used at $337 \mathrm{~nm}$ but not at $266 \mathrm{~nm}$. This matrix has also been used for MALD on a magnetic sector instruments [16].

Chait and co-workers [37] have reported that SA (and other cinnamic acid derivatives) are not well suited for the study of underivatized gangliosides in either the positive or negative ion mode. We could not detect a well-resolved molecular ion signal even for the smallest ganglioside investigated $\left(\mathrm{G}_{\mathrm{M1a}}\right)$ with $\mathrm{SA}$ as matrix, but found DHB to be an efficient matrix for these glycolipids, in both the positive and negative ion modes.
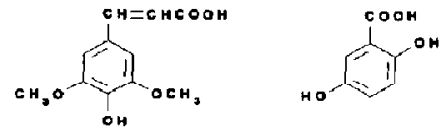

Sinapinic acld (SA) $200,307 \mathrm{~nm}$

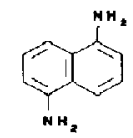

1,5-diaminanaphthalang (DAN) $337 \mathrm{~nm}$

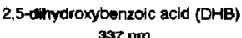
337 inn

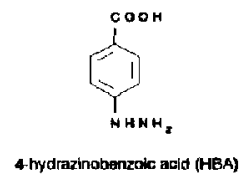

337 กnt

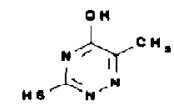

B-Are-2:thiothymine (aTT) 286, 337 non

-

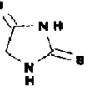

2-thiohydantoln (T-1) $260 \mathrm{~nm}$
Figure 1. Structures of matrices used in the study of underivatized and permethylated gangliosides. 
In the course of other studies, we have found 6-aza2-thiothymine (aTT) to be almost as general a matrix as $\mathrm{DHB}$, and useful for profiling enzymatic digests. It can be used in both the positive and negative ion modes. It has a very strong absorption at $266 \mathrm{~nm}$, and also absorbs well at $337 \mathrm{~nm}$. 1,5-Diaminonaphthalene (DAN) is one of the specialized matrices that work well in the negative ion mode, but not in the positive ion mode. In addition, it seemed to favor glycolipids over proteins or peptides. It was quite difficult to obtain negative ion spectra of proteins with DAN, and any attempt to use small peptides as internal standards for the analysis of glycolipids failed with this matrix. SPECIAL CARE SHOULD BE TAKEN with 1,5-diaminonaphthalene, it being both toxic and a carcinogen. 4-Hydrazinobenzoic acid (HBA) is similar to DAN, in that it is a negative ion mode matrix, with lower efficiency for proteins and peptides. 2-Thiohydantoin (TH) has been used in our laboratory for desorption of peptides and proteins in the positive ion mode, and somewhat poorer performance was found in the negative ion mode. It did not work well for the underivatized gangliosides in either mode, but proved to be very efficient for the permethylated analogs in the positive ion mode.

\section{Sample Preparation}

Several simple sample preparation methods had to be tried in order to obtain the best mass spectra. Gangliosides are not soluble in water; most frequently these are dissolved in a methanol-chloroform $\left(\mathrm{CHCl}_{3}: \mathrm{MeOH}\right)$ mixture. Although all the matrices listed above could be dissolved in 50:50 $\mathrm{CHCl}_{3}: \mathrm{MeOH}$, the rapid evaporation of this solvent did not allow matrix and sample to crystallize together. Cocrystallization is thought to have crucial importance for the success of the MALD analysis [11], but in the presence of the solvent mixtures usually used for matrices (water containing a small percentage of methanol or acetonitrile) the glycolipids visibly precipitated and poor results were obtained. The best results were obtained when matrices were dissolved in 50:50 acetonitrilewater mixture at approximately $10 \mathrm{~g} / \mathrm{L}$ concentration. TH, aTT, and DAN dissolve quite slowly, but the solution process may be hastened by warming the solvents. It is recommended to make fresh solutions every one or two days from SA, DAN, and HBA. The others seem to be quite stable in solution, but, to prevent unforseen problems, fresh solutions of DHB, aTT, and TH were made weekly. The matrix solution $(0.5-1 \mu \mathrm{L})$ was put onto the probe tip and ca. $0.5 \mu \mathrm{L}$ of the ganglioside solution was added on the probe tip. For an instant the liquid phase turned opaque, but soon became clear, indicating that the matrix and the glycolipids were retained in solution. Although the solubility of various gangliosides optimizes at different solvent compositions, $50: 50 \quad \mathrm{CHCl}_{3}: \mathrm{MeOH}$ was found to work well for all. The concentration selected for the ganglioside solutions varied with the sensitivity of the sample. For underivatized gangliosides it was typically $0.1 \mathrm{~g} / \mathrm{L}$, and for the permethylated derivatives one order of magnitude lower. The samples were dried at room temperature without any additional intervention into the drying process. Acceleration of drying was observed to have no or slightly detrimental effect on the quality of the mass spectra. Direct observation of the sample during the experiment was important because the sample surfaces formed by the majority of matrices were inhomogeneous, a phenomenon that seems related to irregular analyte distribution in the matrix and leads to strongly positiondependent quality and sensitivity of the mass spectra.

\section{Spectra of Underivatized Gangliosides}

Mass spectra of underivatized gangliosides were recorded under a variety of experimental conditions (matrices, wavelength, sample preparation). A summary of the experimental results is compiled in Table 2. In the columns are shown the different gangliosides containing up to five sialic acid residues. In the rows are the matrices tried with the given glycolipid in the positive and negative ion modes. Double check marks (w) show whether the corresponding mass spectrum had good signal-to-noise ratio and a well-defined molecular ion peak, so that the two homologs due to the ceramide inhomogeneity could be clearly distinguished and their masses accurately assigned. Cationization was always the major pathway of ionization of glycolipids in the positive ion mode, and even in the negative ion mode peaks containing sodium and potassium could be observed. Ambiguity in mass assignment arose when adduct peaks became more difficult to separate at higher mass and their unresolved contribution shifted the molecualr ion peak centroid. When the LCBs differ by two methylene units, the $[\mathrm{M}+\mathrm{Na}-2 \mathrm{H}]^{-}$peak of the lower homolog differs only by $6 \mathrm{u}$ from the $[\mathrm{M}-\mathrm{H}]^{-}$peak of the higher homolog. In order to resolve these two peaks in the spectrum of the ganglioside $\mathrm{G}_{\mathrm{Q} 1 \mathrm{~b}}$, mass resolution better than 1:400, a performance usually not attained for MALD with linear TOF analyzers with these samples, would be needed. In cases where the molecular ion region was present but the peaks were not well resolved, the entry in Table 2 is a single check mark (w). Dashes indicate that no molecular ion signal was observed.

As has been observed for FAB ionization [22, 41], negative ion mode MALD was found to be more suitable than positive ion mode operation for the mass spectrometry of gangliosides. Although the amount of sample put on the probe tip was the same in the positive and negative ion modes (about $50 \mathrm{ng}$ ), more abundant molecular ion peaks and better resolution were found in the negative ion mode and lower laser irradiance was required. Even $[\mathbf{M}-\mathbf{H}]^{-}$ions underwent fragmentaion easily, but metastable decomposi- 
Table 2. Summary of matrix-assisted laser desorption results on underivatized gangliosides ${ }^{\mathrm{a}}$

\begin{tabular}{|c|c|c|c|c|c|c|c|c|}
\hline Matrix & Mode & $\lambda(\mathrm{nm})$ & $\mathbf{G}_{M 1 a}$ & $G_{D 1 a}$ & $\mathrm{G}_{\mathrm{D} \text { Ib }}$ & $\mathrm{G}_{\mathrm{T1b}}$ & $G_{a 1 b}$ & $G_{p 1}$ \\
\hline \multirow[t]{2}{*}{$\mathrm{SA}$} & + & 337 & - & - & - & - & - & - \\
\hline & - & 337 & $\nu$ & - & - & - & - & - \\
\hline \multirow[t]{2}{*}{ DHB } & + & 337 & אי & מ & מ & 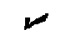 & 以 & - \\
\hline & - & 337 & ロ & $r$ & & r & מr & $\sim$ \\
\hline \multirow[t]{4}{*}{$\mathrm{aTT}$} & + & 337 & w & مמس & אמאמ & مر & $\omega$ & - \\
\hline & & 266 & $w$ & - & $n / a$ & $\mathrm{n} / \mathrm{a}$ & $n / a$ & $\mathrm{n} / \mathrm{a}$ \\
\hline & - & 337 & מט & r & 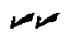 & w & $r$ & - \\
\hline & & 266 & $w$ & $\mathrm{n} / \mathrm{a}$ & $\mathrm{n} / \mathrm{a}$ & $\mathrm{n} / \mathrm{a}$ & $\mathrm{n} / \mathrm{a}$ & $\mathrm{n} / \mathrm{a}$ \\
\hline \multirow[t]{2}{*}{ DAN } & + & 337 & - & - & - & - & - & - \\
\hline & - & 337 & w & מ & w & מ & $r$ & - \\
\hline \multirow[t]{2}{*}{ HBA } & + & 337 & - & - & - & - & - & - \\
\hline & - & 337 & rr & $r$ & سמس & Wr & r & 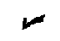 \\
\hline
\end{tabular}

a Strang molecular ion signal is indicated by of molecular ions by - " $n$ / $a$ " indicates that the corresponding combination was not measured.

tion was absent, and the background was therefore much cleaner than in the positive ion mass spectra. With an increasing number of sialyl residues (from $G_{M 1 \text { n }}$ toward $G_{P 1}$ ), the quality of the negative ion mass spectra declined and thus the difference between positive and negative ion spectra became less and less significant. Even so, recording useful spectra from $G_{P 1}$ was easy in the negative ion mode (with $\mathrm{DHB}$ and IBA matrices), apart from resolution problems brought about by strong adduct formation, whereas no positive ion MALD mass spectra could be obtained for this compound.

The most frequently observed fragmentation of the molecular ions involves the loss of one or more sialic acid residues. Two types of this decomposition could be found in MALD ionization spectra. In almost every case Y-type fragmentation [35] occurred, as the glycosidic bond between Neu5Ac and the Gal residue in the root sugar was cleaved, with retention of the hydroxyl group on Gal. The fragment ions appeared 291 u lower than the $[\mathrm{M}-\mathrm{H}]^{-}$ions. The fragmentation nomenclature for the carbohydrate portion of glycolipids is indicated in Scheme I. Another common fragmentation pathway was signaled by loss of 45 u, probably due to decarboxylation. This process seemed to depend on a number of experimental parameters, such as wavelength, laser power, matrix/analyte ratio, and the matrix itself. It could be observed frequently with aI'T and sometimes with DAN, HBA, and DHB. Loss of a water molecule from the molecular ions was probably indicative of lactone formation, favored because of the proximity of the carboxyl groups of Neu5Ac residues and one of the $\mathrm{OH}$ groups on the neighboring $\mathrm{Gal}$ residues. Although this process occurs spontaneously in solution and is frequently detectable in FAB mass spectra [25], only the gangliosides $G_{D 1 a}$ and $G_{D 1 b}$ exhibited this behavior in MALD ionization spectra. Repeated analyses of these compounds exhibited widely varying abundance of the lactone peaks, suggesting that gas phase processes were involved rather than solution chemistry.

Smaller Gangliosides at Low Laser Power. Many matrices produced clean spectra for the ganglioside $G_{M 1 a}$ in the negative ion mode, and that recorded using 1,5diaminonaphthalene (DAN) is shown in Figure 2. The baseline is uninterrupted in this spectrum down to the region of matrix peaks. With aTT matrix negative ion mass spectra of good quality were obtained at $266 \mathrm{~nm}$ and $337 \mathrm{~nm}$, and no wavelength dependence of the spectra was observed (unlike the positive ion mass spectra, which will be discussed later). The third tiny
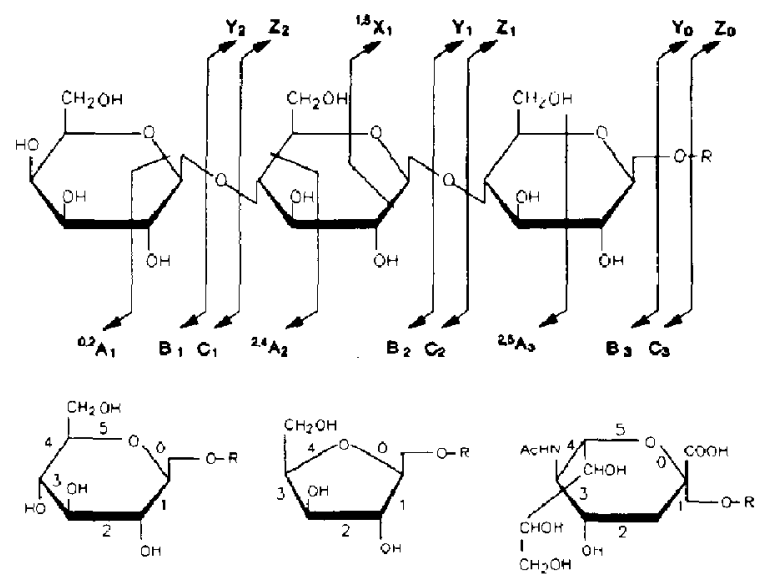

Scheme I. Designations for product ions that arise from fragmentations within the carbohydrate portion of glycolipids. Because the number of hydrogen transfers during ring cleavages $\left(\mathrm{A}_{n}, \mathrm{X}_{n}\right)$ can vary, these are not included in the designations, but must be indicated in cach case. Fragments that arise via glycosidic cleavages include predictable numbers of hydrogen transfers; the designations are thus defined; $\mathrm{B}_{i}^{+}=\left[\mathrm{B}_{i}\right], \mathrm{C}_{i}^{+}=\left[\mathrm{C}_{i}+2 \mathrm{H}\right]$, $\mathrm{Y}_{j}^{+}=\left[\mathrm{Y}_{j}+2 \mathrm{H}\right], \mathrm{Z}_{i}^{+}=\left[\mathrm{Z}_{j}\right] ; \mathbf{B}_{i}^{-}=\left[\mathrm{B}_{i}-2 \mathrm{H}\right], \mathrm{C}_{i}^{-}=\left[\mathrm{C}_{i}\right], \mathrm{Y}_{j}^{-}=\left[\mathrm{Y}_{i}\right]_{,}$ $Z_{j}^{-}=\left[Z_{j}-2 H\right]$. Reproduced, with permission, from ref 45 . 


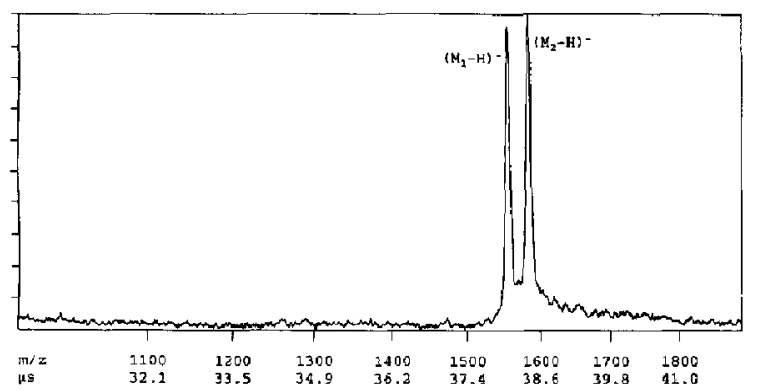

Figure 2. Negative ion MALD mass spectrum of the ganglioside $G_{M 1 a}$ recorded with DAN matrix, $337-\mathrm{nm}$ irradiation. $\mathrm{M}_{1}$ and $\mathrm{M}_{2}$ are two homologs corresponding to the gangliosides having d18:1 and d20:1 sphingoid bases. $\left[\mathrm{M}_{1}-\mathrm{H}\right]^{-}=\mathrm{m} / \mathrm{z} 1545.2$ and $\left[\mathrm{M}_{2}-\mathrm{H}\right]^{-}=m / z 1573.2$ was found; the calculated values are shown in Table 1 .

peak, $14 \mathrm{u}$ higher than the peak attributed to the lower homolog, between the molecular ion peaks probably represents an additional inhomogeneity in the LCB.

Figure 3 shows the negative ion mass spectrum of $\mathrm{G}_{\mathrm{ma}}$ with HBA matrix. In addition to the intact molecular ions both $Y$ - and Z-type loss of a Neu5Ac residue could be observed (excluding or including the glycosidic oxygen [35]). Although not seen in this spectrum, minor dehydration of the $[\mathrm{M}-\mathrm{H}]^{-}$ions, probably due to lactone formation, was sometimes detected. Decarboxylated peaks accompany the molecualr ions at $[\mathrm{M}-\mathrm{H}-45]^{-}$. Decarboxylation and lactone formation would be competitive reactions if they involve the same carboxyl grnup.

Fragmentation Increase at Higher Laser Power. Despite the pour quality of positive ion mass spectra of underivatized gangliosides, differences in fragmentation patterns could be clearly observed for isomers. The ganglioside $\mathrm{G}_{\mathrm{D} 1 \mathrm{a}}$ contains two sialic acid substituents, one bonded to each of the root sugar residues II and IV. In

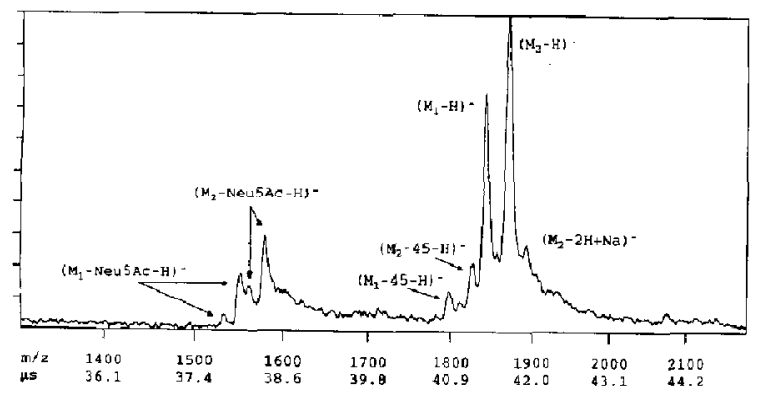

Figure 3. Negative ion MALD mass spectrum of the ganglıside $G_{D 1}$ with $\mathrm{HBA}$ matrix at 337-nm irradiation. Loss of a Neu5AC residue takes place as fragmentation of the type $Y_{2 \beta}$ and /or $Y_{4 \alpha}$ and $Z_{2 \beta}$ and /or $Z_{4 \alpha}$. $Y$ and $Z$ fragments differ by 18 $u$, but $2 \beta$ and $4 \alpha$ fragments have the same mass because these represent isomers. $\mathrm{M}_{1}-\mathrm{d} 18: 1, \mathrm{M}_{2}-\mathrm{d} 20: 1 .\left[\mathrm{M}_{1}-\mathrm{H}\right]^{-}=m / 2$ 1838.4 and $\left[\mathrm{M}_{2}-\mathrm{H}\right]^{-}=m / z$ 1866.3.
$G_{D 1 a}$ the two sialyl groups have identical linkages to the tetrasaccharide chain and thus a glycosidic cleavage of either sialic acid residues would be (at least approximately) equally probable. Because a single cleavage is more likely than two cleavages, one would expect a more abundant peak of $[\mathrm{M}-\mathrm{Neu} 5 \mathrm{AC}+\mathrm{Na}]^{+}$ than $[\mathrm{M}-2 \mathrm{Neu} 5 \mathrm{Ac}+\mathrm{Na}]^{+}$. Compound $\mathrm{G}_{\mathrm{D} 1 \mathrm{~b}}$ has a single disialyl substituent (Neu5Aca(2-8)Neu5Ac $\alpha 2$-) on Gal II. The 2-8 linkage between the two sialyl residues seems more resistant to fragmentation than the 2-3 linkage to Gal II or Gal IV, so in the mass spectrum of $G_{D 1 b}$ the major fragment ion observed is $[\mathrm{M}-2 \mathrm{Neu} 5 \mathrm{AC}+\mathrm{Na}]^{+}$. The comparison is shown in Figure 4 for the mass spectra recorded with DHB matrix. Although laser fluence had to be increased in order to make the difference in fragmentation pattern more clear cut, which degraded the overall quality of the spectra, this way of distinguishing isomers is still effective and requires a minimal amount of sample and time.

Wavelength Dependence of Fragmentation. In Figure 5 are shown the positive ion mass spectra of the ganglioside $\mathrm{G}_{\mathrm{Mla}}$ obtained with the aTT matrix. The comparison is made at two different wavelengths: 337 and 266 $\mathrm{nm}$. The most obvious difference between the two spectra is the extent of fragmentation. While at $337 \mathrm{~nm}$ only minor fragment peaks show up, at $266 \mathrm{~nm}$ frag-
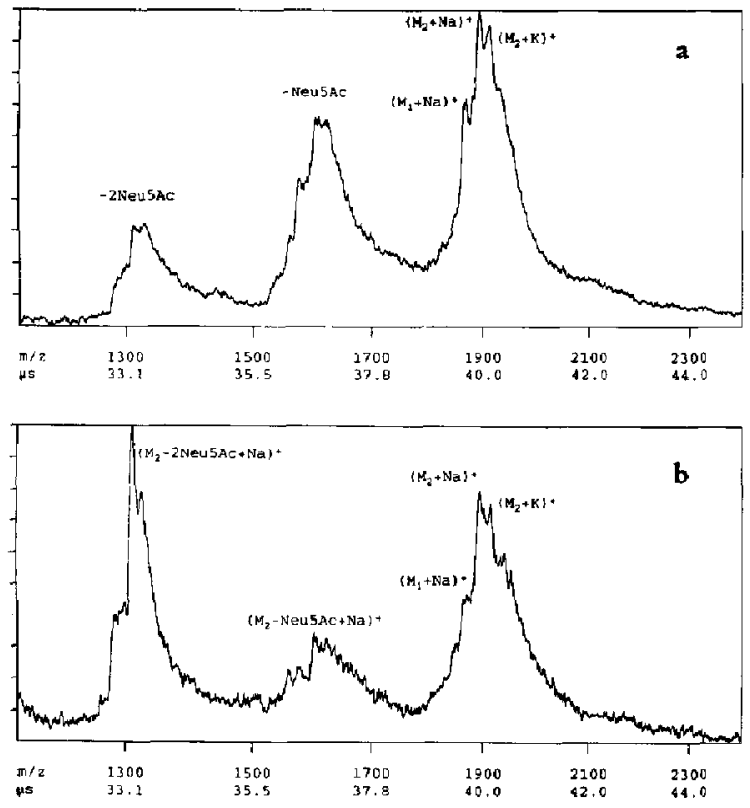

Figure 4. High laser power positive ion MALD mass spectra of gangliosides (a) $G_{D 1 a}$ and (b) $G_{D 1 b}$ reveal different fragmentation patterns for the two isomers. Both spectra were recorded with DHB matrix, 337-nm irradiation. $\mathrm{M}_{1}-\mathrm{d} 18: 1, \mathrm{M}_{2}-\mathrm{d} 20: 1$. $\left[\mathrm{M}_{1}+\right.$ $\mathrm{Na}^{+}=m / z \quad 1867.8$ and $\left[\mathrm{M}_{2}+\mathrm{Na}^{+}=m / z 1894.7\right.$ was found from (a). The slightly larger error in mass assignment was due to the high laser irradiance applied. 

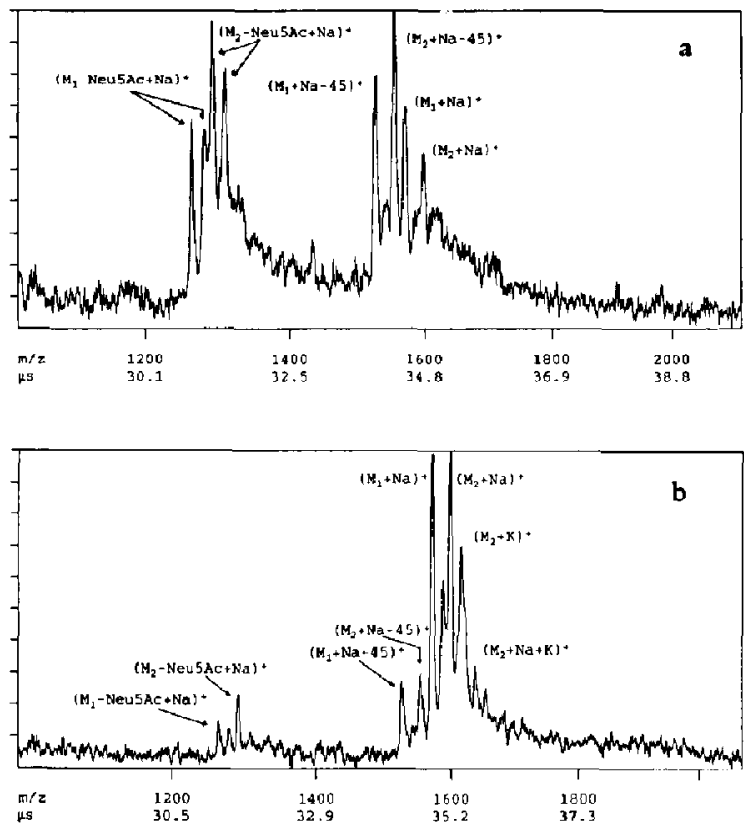

Figure 5. Positive ion MALD mass spectra of the ganglioside $G_{M 1 \text { a }}$ at (a) $266 \mathrm{~nm}$ and (b) $337 \mathrm{~nm}$. In both cases aTT matrix was used. The time scale shift between (a) and (b) is due to the different timing of the detection with the two lasers. Both $\mathrm{Y}$ - and Z-type cleavage of Neu5Ac occurs. $M_{1}-\mathrm{d} 18: 1, \mathrm{M}_{2}-\mathrm{d} 20: 1$. $\left[\mathrm{M}_{1}+\mathrm{Na}\right]^{+}=m / z \quad 1570.2$ and $\left[\mathrm{M}_{2}+\mathrm{Na}\right]^{+}=m / z 1597.2$ determined from (a).

ment ions are the most abundant. In the molecular ion region the decarboxylated peaks are more abundant than the $[\mathrm{M}-\mathrm{H}]$ ions themselves. Similar differences in the extent of decarboxylation have also been observed for peptides with aTT matrix. Spectra recorded with 337 and $266 \mathrm{~nm}$ desorption also differ in the way the sialyl residues are lost. While in the former case there occurs only Y-type fragmentation (loss of $291 \mathrm{u}$ ), in the latter both $Y$ - and Z-type fragments can be found (loss of 291 and $309 \mathrm{u}$ ). In this "desialylated" region no pairs of peaks can be observed differing by $45 \mathrm{u}$, corroborating the assumption that loss of $45 \mathrm{u}$ can be attributed to decarboxylation. Because aTT was the only matrix operational at both wavelengths it is not known whether the differences seen in Figure 5 should be considered general or matrix specific.

Matrix-Dependent Fragmentation. The negative ion mass spectra of the gangliosides $G_{D 1 a}$ and $G_{D 1 b}$ exhibited a variety of fragmentation processes depending on the matrix and, to a lesser extent, on the spot chosen for irradiation. Though the sensitivity and resolution were better in the negative ion mode, molecular ions of these compounds decomposed very easily. The abundance of fragment ions varied from spot to spot on the probe surface and was found to be strongly dependent on the matrix (a tentative order being DHB $<\mathrm{HBA}<$ aTT $<$ DAN with some dependence on the sample).

Figure 6 shows the negative ion mass spectra of $\mathrm{G}_{\mathrm{Dlb}}$ with matrices $\mathrm{DHB}$ and DAN. In contrast to DHB, DAN strongly promotes the Y-type loss of Neu5Ac (in this respect aTT is similar to DAN). In both matrices, lactone formation is again observable. Mass spectra of $G_{D 1 a}$ with DHB were very similar to that in Figure 3 , while more pronounced fragmentation would be observed with aTT and DAN matrices.

Larger Gangliosides. In contrast to the spectra of gangliosides containing two sialic acid residues, the negative ion mass spectra of the trisialo ganglioside $\mathrm{G}_{T 1 \mathrm{~b}}$ revealed only minor fragmentation. The spectra recorded with $D H B$ or HBA as matrix were not much different from those of $G_{D 1 a}$ and $G_{D 1 b}$. However, the spectra with aTT or DAN as matrix looked completely different. Figure 7 shows the mass spectrum of $\mathrm{G}_{\mathrm{Tl}}$ with DAN matrix. No trace of fragmentation is seen, and the most abundant peaks correspond to $[\mathrm{M}-2 \mathrm{H}$ $+\mathrm{K}^{-}$as deduced from calibration to the matrix peaks. But there remained the faint possibility of misassignment, because the centroid of the peak $\left[\mathrm{M}+\mathrm{Cl}^{-}\right.$(the individual carbon and chlorine isotopic peaks cannot be resolved) would differ by about $2 \mathrm{u}$ from the $[\mathrm{M}-2 \mathrm{H}+\mathrm{K}]^{-}$. $[\mathrm{M}+\mathrm{Cl}]^{-}$ions have been reported to appear in the negative ion MALD ionization spectra of oligosaccharides [37]. In the accompanying spectra ob-
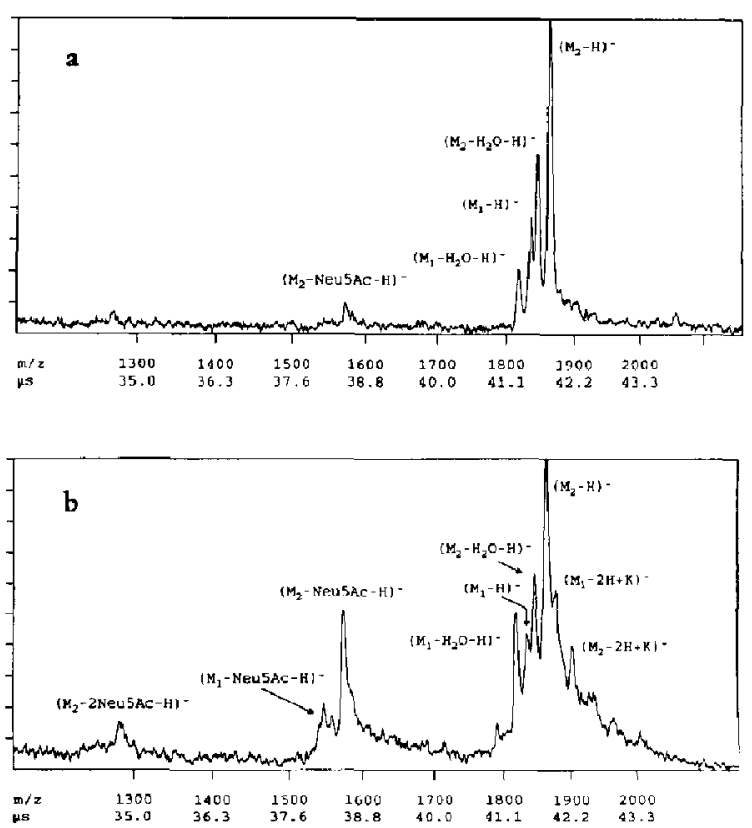

Figure 6. Negative ion MALD mass spectra of the ganglioside $G_{\text {DIb }}$ with (a) DHB and (b) DAN matrices, 337-nm irradiation. $\mathrm{M}_{1}-\mathrm{d} 18: 1, \mathrm{M}_{2}-\mathrm{d} 20: 1 .\left[\mathrm{M}_{1}-\mathrm{H}\right]^{-}=m / z 1835.7$ and $\left[\mathrm{M}_{2}-\right.$ $\mathrm{H}^{-}=m / z$ 1863.6 determined from (a). 


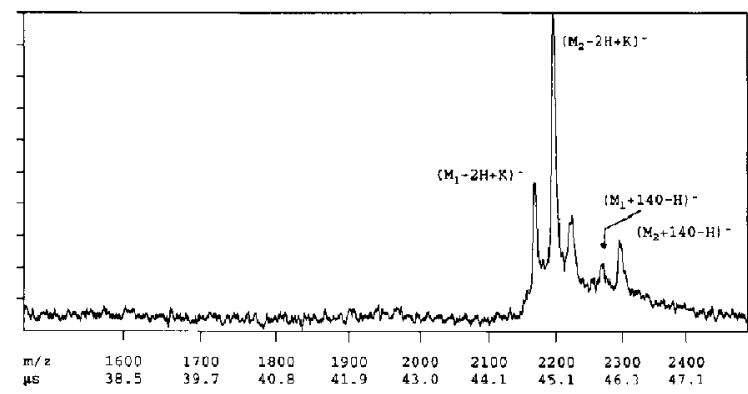

Figure 7. Negative ion MALD mass spectrum of the ganglioside $G_{T 1 b}$ with DAN matrix, $337-n m$ irradiation. $M_{1}-d 18: 1$, $\mathrm{M}_{2}-\mathrm{d} 20: 1$. $\left[\mathrm{M}_{1}+\mathrm{K}-2 \mathrm{H}\right]^{-}=m / z \quad 2165.8$ and $\left[\mathrm{M}_{2}+\mathrm{K}-\right.$ $2 \mathrm{H}]^{-}=m / z 2193 . \%$ was found.

tained with aTT as matrix (not shown), [M $-\mathrm{H}^{-}$ peaks were also found, and these could be used as additional internal standards, leading to a very accurate mass determination for the adduct ion. With that calibration it was unambiguous that the most abundant peaks in all these spectra corresponded to [M $2 \mathrm{H}+\mathrm{K}]^{-}$and not to $\left[\mathrm{M}+\mathrm{Cl}^{-}\right.$. The peaks $140 \mathrm{u}$ higher than the calculated values of the $[\mathrm{M}-\mathrm{H}]^{-}$ions in Figure 7 are probably due to matrix adduction accompanied by water loss.

The complete absence of fragmentation in the spectrum in Figure 7 suggested that elevating the potassium level in the sample could prevent the decomposition observed when $G_{D 1 a}$ and $G_{D 1 b}$ were analyzed with DAN matrix (Figure 6b), by favoring the formation of $\left[\mathrm{M}-2 \mathrm{II}+\mathrm{K}^{-}\right.$over the less stable $[\mathrm{M}-\mathrm{H}]^{-}$. To explore this question a 20-fold (molar) excess of KI was added to the $\mathrm{G}_{\mathrm{Dla}}$ sample, but this step did not result in reduction of the abundance of the desialylated peaks.

For underivatized gangliosides, the spectrum quality deteriorated as the number of sialic acid substituents increased. The numerous possible combinations of adduct peaks produced an unresolved complex in many cases. In the negative ion mass spectrum of the ganglioside $G_{\mathrm{O} 1 \mathrm{~b}}$, shown in Figure $8 \mathrm{a}$, the ions $\left[\mathrm{M}_{1}-2 \mathrm{H}+\mathrm{Na}\right]^{-}$and $\left[\mathrm{M}_{2}-\mathrm{H}\right]^{-}$could no longer be resolved, resulting in a shift of the mass assignment. The centroids of the two $\left[\mathrm{M}_{n}-\mathrm{H}\right]^{-}$peaks were found $26 \mathrm{u}$ apart, instead of $28 \mathrm{u}$, due to the contribution from the unresolved $\left[\mathrm{M}_{1}-2 \mathrm{H}+\mathrm{Na}^{-}\right.$ion. The decline in resolution was accompanied by a decline of sensitivity, but spectra were still relatively easy to obtain with DHB and HBA. The matrices aTT and DAN were less satisfactory for the ganglioside $G_{\mathrm{Qlb}}$ and both of them failed with $\mathrm{G}_{\mathrm{P1}}$. Figure $8 \mathrm{~b}$ shows the mass spectrum of $G_{P 1}$ recorded with $D H B$ as matrix. In this spectrum, no single peaks can be recognized under the envelope. The centroid of this wide peak $(m / z 2789)$ is substantially higher than the value calculated for $[\mathrm{M}-\mathrm{H}]^{-}$(see Table 1), indicating that adduct formation involved multiple sodium and potassium cations. When HBA was used as the matrix, the two homologs could be clearly distinguished, but
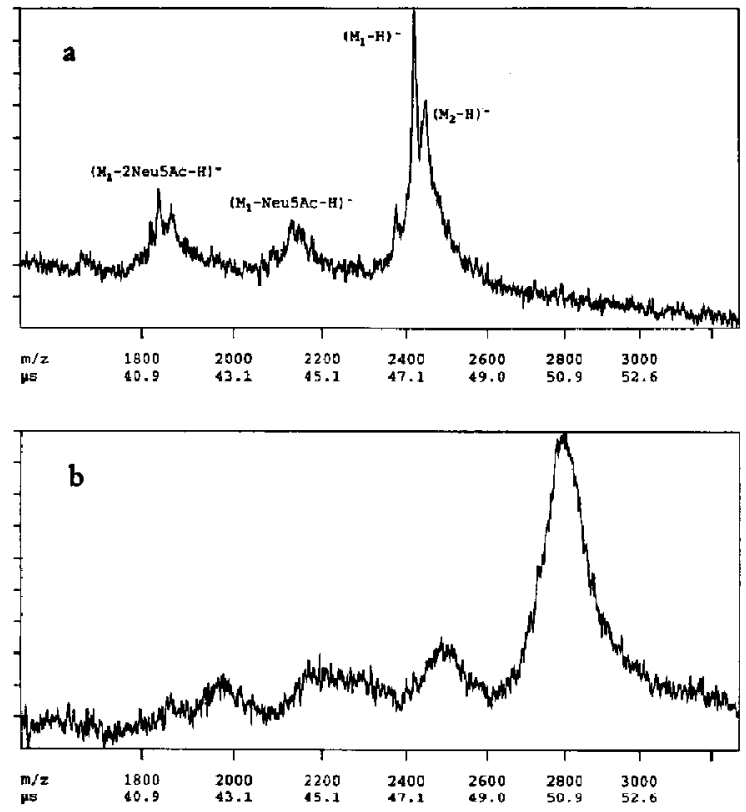

Figure 8. Negative ion MALD mass spectra of gangliosides (a) $\mathrm{G}_{\mathrm{Q} 1 \mathrm{~b}}$ and (b) $\mathrm{G}_{\mathrm{P} 1}$ with $\mathrm{DHB}$ matrix, $337-\mathrm{nm}$ irradiation. $\mathrm{M}_{1}-$ d18:1, $\mathrm{M}_{2}-\mathrm{d} 20: 1$. For $\mathrm{G}_{\mathrm{Q} 1 \mathrm{~b}}\left[\mathrm{M}_{1}+\mathrm{Na}^{+}=m / z\right.$ 2419.6. $\left[\mathrm{M}_{2}+\right.$ $\mathrm{Na}]^{+}=m / z 2445.8$. For $\mathrm{G}_{\mathrm{P} 1}$ the peak centroid is at $m / z 2794$.

the sensitivity was somewhat lower, and the baseline was uneven and noisy because of extensive metastable decay.

It became increasingly difficult to obtain spectra in the positive ion mode with underivatized gangliosides containing 4 and 5 sialyl residues. The positive ion spectrum of the $G_{Q 1 b}$ recorded with $D H B$ as matrix was as good as its negative ion spectrum but the other matrices failed in the positive ion mode, and no positive ion signal of $G_{P 1}$ could be obtained with any of the matrices.

Mixture Analysis. Because MALD ionization was shown to produce mostly molecular ion signals, especially in matrices chosen for this characteristic, it seemed worthwhile to investigate its suitability for detecting the distribution of components present in a typical ganglioside mixture obtained by extraction from a tissue sample and to compare the results with other methods. For this purpose, a well-characterized sample of ganglioside antigens expressed by subsets of rat dorsal root ganglions [41] was used. The structure of the antigen is given below:

$\begin{array}{cc}\text { Gal } \alpha 1 \rightarrow 3 \mathrm{Gal} \beta 1 \rightarrow 3 \mathrm{GalNAc} \beta 1 & \rightarrow 4 \mathrm{Gal} \beta 1 \rightarrow 4 \mathrm{Glc} \beta 1 \rightarrow 1^{\prime} \mathrm{Cer} \\ 2 & 3 \\ \uparrow & \uparrow \\ 1 \alpha \mathrm{Fuc} & 2 \alpha \text { Neu } 5 \mathrm{Ac}\end{array}$


In this ganglioside mixture, a single LCB, $4 E$-sphingenine, is present, but there is considerable heterogeneity in the fatty acyl group, with 16:0 being the major component and 20:0, 22:1, 22:0, 24:1, 24:0 and 26:1, 26:0 and 28:0 being minor components [41]. A 1-2 $\mu \mathrm{g}$ sample of the mixture of native fucosyl monosialogangliosides remained from the earlier structural studies. This was dissolved in $200 \mu \mathrm{L} 1: 1 \mathrm{CHCl}_{3}: \mathrm{MeOH}$ and $1 \mu \mathrm{L}$ of this solution was mixed with $1 \mu \mathrm{L}$ DHB $(10 \mathrm{~g} / \mathrm{L})$ to obtain the spectrum shown in Figure 9. The distribution of molecular species in Figure 9 parallels that observed in the negative ion FAB mass spectrum [41] but required only about $0.5 \%$ of the amount used for the previous FAB-MS analysis.

\section{Spectra of Permethylated Gangliosides}

Permethylation is a widely used method to improve mass spectrometric sensitivity, or to enhance volatility for ionization techniques that require the sample molecules to be in the gas phase. According to scattered reports [37] similar derivatization procedures (e.g. peracetylation) improve the sensitivity of matrixassisted laser desorption in cases where the original samples are hard to ionize. MALD ionization spectra of the permethylated gangliosides $G_{D 1 b}$ and $G_{T 1 b}$ were recorded with several matrices in the positive ion mode. Permethylation considerably increased the sensitivity. For underivatized gangliosides, about $50 \mathrm{ng}$ was used for each set of spectra, to achieve optimum results. One tenth this sample level was still sufficient for the detection of the underivatized compounds (with the possible exception of $G_{P 1}$ ). The estimated improvement in sensitivity with the permethylated sample was around 100 -fold. Very high sensitivity was obtained with 2-thiohydantoin as matrix at $266 \mathrm{~nm}$. This increase in sensitivity is reflected by the fact that even sinapinic acid could now be used as matrix.

Two spectra of the permethylated ganglioside $\mathrm{G}_{\mathrm{T} 1 \mathrm{~b}}$ with sinapinic acid (337 $\mathrm{nm})$ and 2-thiohydantoin (266

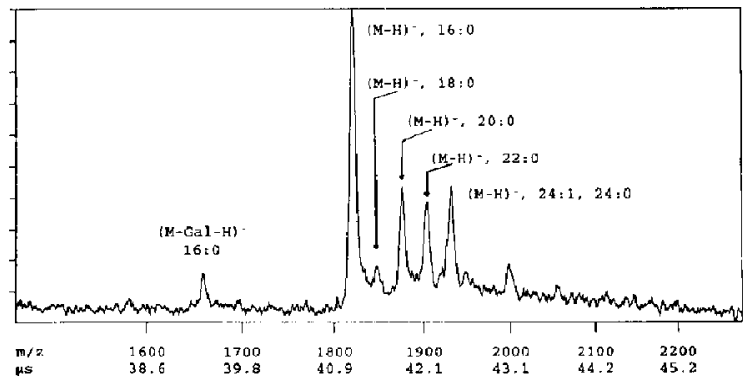

Figure 9. Negative ion MALD mass spectrum of the $\alpha$-galactose ( $\alpha$-fucose)-monosialo-gangliosides expressed by subsets of rat dorsal root ganglion neurons [41], in DHB matrix, 337-nm irradiation. The only LCB present is $4 E$-sphingenine. Numbers shown represent fatty acyl variants. Mass assignments of observed peaks include $[\mathrm{M}-\mathrm{H}]^{-}: 16: 0 \mathrm{~m} / \mathrm{z}$ 1826.6, 18:0 $\mathrm{m} / \mathrm{z}$ 1854.2, 20:0 $\mathrm{m} / \mathrm{z}$ 1882.4, 22:0 $\mathrm{m} / \mathrm{z}$ 1910.3, and $24: 0$ plus $24: 1 \mathrm{~m} / \mathrm{z}$ 1938.0. nm) matrices are shown in Figure 10. Comparison of the molecular ion abundances relative to that of the matrix ions suggests that the ionization of the sample is more efficient in 2-thiohydantoin. The sensitivity with the latter matrix was excellent; indeed, $10 \mathrm{fmol}$ of permethylated $\mathrm{G}_{\mathrm{T} 1 \mathrm{~b}}$ ( $26 \mathrm{pg}$ ) still produced well-defined spectra with this matrix. In all cases $[\mathrm{M}+\mathrm{Na}]^{+}$and $[\mathrm{M}+\mathrm{K}]^{+}$were the most abundant ions. A few peaks indicating incomplete methylation were also present. Low-abundance peaks due to permethylated components lacking one sialic acid residue could be seen in both cases. Improving sensitivity is often concomitant with better mass resolution; a comparison of the observed mass resolution also testifies to the improvement in the quality of the MALD mass spectra upon permethylation. For the underivatized $\mathrm{G}_{\mathrm{T} 1 \mathrm{~b}}$ the highest mass resolution (full width at half maximum) attained was about 1:250, while in the spectrum with 2-thiohydantoin matrix shown in Figure $10 \mathrm{~b}$ the mass resolution at the $[\mathrm{M}+\mathrm{Na}]^{+}$peak of the higher homolog was 1:320. From a mechanistic point of view, it is interesting to consider that the analytes in this example were glycolipids with all their polar sites blocked and the matrix had no carboxyl groups, yet the sensitivity and resolution were in the same range as that reported for peptides and proteins in the most favorable matrices!

\section{Conclusions}

Accumulating experience in matrix-assisted laser desorption yields heightened awareness of the experi-
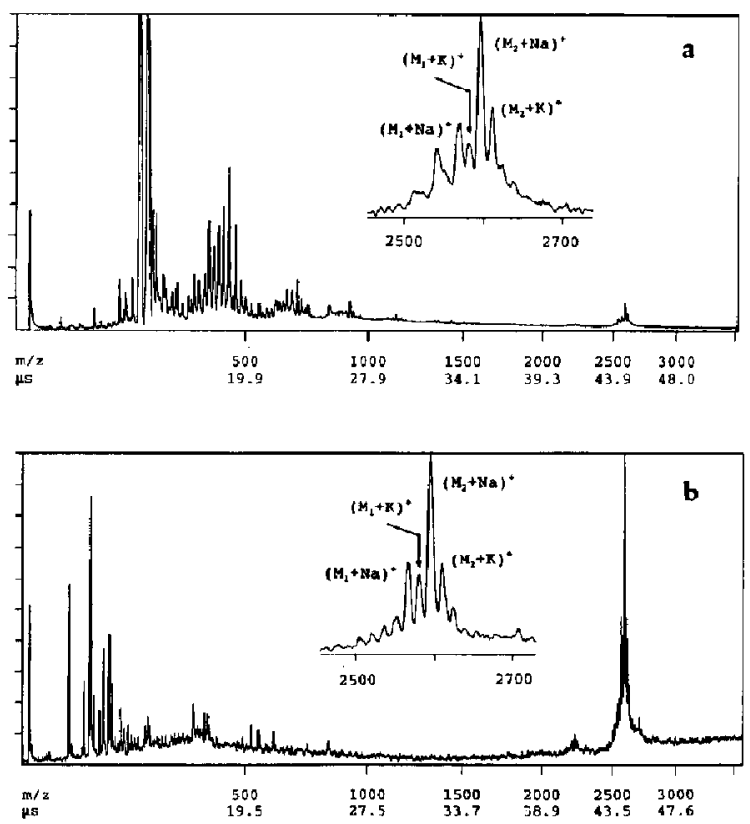

Figure 10. Positive ion MALD mass spectra of the permethylated ganglioside $G_{T 1 b}$ with (a) $S A$ at $337 \mathrm{~nm}$, and (b) TH matrix at 266-nm irradiation. Inserts show the expanded molecular ion region. $\mathrm{M}_{1}-\mathrm{d} 18: 1, \mathrm{M}_{2}-\mathrm{d} 20: 1 .\left[\mathrm{M}_{\mathbf{1}}+\mathrm{Na}\right]^{+}=m / z$ 2576.0. $\left[\mathrm{M}_{2}\right.$ $+\mathrm{Na}]^{+}=m / z 2603.9$ determined from (b). 
mental subtleties pertinent to optimization of the ionization process and their effects on the appearance of the spectra. This study has shown that the MALD ionization process is well suited for the study of gangliosides, producing molecular ions at the picomole level for underivatized samples and at the low femtomole level for permethylated derivatives. It has also brought to light points not in accord with some of the general statements made at the outset regarding the characteristics of MALD ionization. In particular, these results show that it is not always possible to avoid fragmentation of the molecular ions and that optimum sample preparation involves purification or derivatization steps and may require methodological developments so far as search for the most appropriate matrix-wavelength combination is concerned. Neither of these features, however, necessarily represents a drawback. Occurrence of fragmentaion may bear structural information. It seems very important to base the choice of matrix on the given problem. The multiplicity of matrices in these studies proved informative, since the fragmentation processes have been observed to depend on the matrix. It is clear that utilizing alternative matrices can simplify mixture analyses when fragment or adduct peaks complicate the mass spectra. More involved sample preparation methods will certainly widen the scope of problems amenable to MALD-TOF, and could confer selectivity.

The studies reported here demonstrated the following: (1) The sensitivity of MALD ionization for molecular weight determinations of native and permethylated gangliosides is at least two orders of magnitude better than that of FAB/LSIMS. (2) As in FAB/LSIMS, underivatized gangliosides are ionized more efficiently in the negative ion mode. (3) Fragmentation of the molecular ions of underivatized gangliosides is observed in almost all cases, its extent being dependent on matrix, wavelength, and laser power, and it can provide limited structural information. (4) Permethylation lowers the detection limit for MALD ionization of gangliosides by approximately another two orders of magnitude.

These results offer further evidence that MALD ionization is not only an exotic technique for problems inaccessible to the other mass spectrometric methods but also has an important role to play in applications dominated by $\mathrm{FAB}$ for a decade. The high yields of molecular ions from underivatized and permethylated gangliosides suggest the feasibility of an improved approach to structural studies by MS/MS employing the MALD technique for primary ion generation. For MS/MS, derivatization may not always be required to achieve adequate sensitivity, but it would offer the proven advantage of directing fragmentation into informative channels.

\section{Acknowledgments}

The authors are grateful to $K$. Biemann for his encouragement and support of this work, to J. E. Biller and H. Köchling for experimental and data system refinements that facilitated these studies, and to F. Hillenkamp and his colleagues for helpful discussions. Gangliosides were kindly provided by J.-E. Månsson and L. Svennerholm (Göteborg University, Sweden) and D. K. Chou and F. B. Jungalwala (Eunice Kennedy Shriver Center, Waltham. MA). The MIT Mass Spectrometry Facility is supported by the NIH Center for Research Resources, grant No. RR00317 to K. Biemann. NATO collaborative grant No. 900605 assists MALD TOF MS studies.

\section{References}

1. Karas, M.; Bachmann, D.; Bahr, U.; Hillenkamp, F. Int. J. Mass Spectrom. Ion Proc. 1988, 78, 53-68.

2. Tanaka, K.; Waki, H.; Ido, Y.; Akita, S.; Yoshida, Y. Rapid Commun. Mass Spectrom. 1988, 8, 151.

3. Karas, M.; Bahr, U.; Ingendoh, A.; Hillenkamp, F. Angew. Chem. Intl. Ed. Engl. 1989, 28, 760-761.

4. Chan, T-W. D.; Colbum, A. W.; Derrick, P. J. Org. Mass Spectrom. 1992, 27, 53-56.

5. Hillenkamp, F.; Karas, M.; Beavis, R. C.; Chait, B. T. Anal. Chem. 1991, 63, 193A-1203A.

6. Chait, B. T. Presented at the 4th Sanibel Conference on Mass Spectrometry, Sanibel Island, FL, 1992.

7. Stahl, B.; Steup, M.; Karas, M.; Hillenkamp, F. Anal. Chem. $1991,63,1463-1466$.

8. Overberg, A.; Hassenbürger, A,; Hillenkamp, F. In Mass Spectrometry in Biological Sciences: A Tutorial; Gross, M. L., Ed:; Kluwer Academic Publishers: Amsterdam, 1992, pp $181-197$.

9. James, C. F.; Wilkins, C. L. J. Am. Chem. Soc. 1988, 110, $2687-2688$.

10. Chevrier, M.; Cotter, R. J. Rapid Commun. Mass Spectrom. 1991, 12, 611-618.

11. Strupat, K.; Karas, M.; Hillenkamp, F. Int. J. Mass Spectrom. Ion Proc. 1991, 111, 89-102.

12. Beavis, R. C.; Chait, B. T. Anal. Chem. 1990, 60, 1836-1840.

13. Mamyrin, B. A.; Karatajev, V. J., Shmikk, D. V.; Zagulin, V. A. So0. Phys. JETP 1973, 37, 45-48.

14. Boesl, U.; Weinkauf, R.; Schlag, E. W. Int. I. Mass Spectrom. Ion Proc. 1991, 112, 121-166.

15. Hettich, R. L.; Buchanan, M. V. J. Am. Soc. Mass Spectrom., 1991, 2, 22-28

16. Hill, J. A.; Annan, R. A.; Biemann, K. Rapid Commun. Mass Spectrom., 1991, 6, 395-399.

17. Karlsson, K.-A. Ann. Rev. Biochem. 1989, 58, 309-350.

18. Sweeley, C. C. In Biochemistry of Lipids, Lipoproteins, and Membranes; Vance, D. E., Vance, J., Eds.; Elsevier Science: Amsterdam, 1991; PP 327-361.

19. Hakomori, S. Pure Appl. Chem. 1991, 63, 473-482.

20. Iwamori, M.; Nagai, Y. Biochim. Biophys. Acta 1978, 528, 257-267.

21. Oettgen, E. F., Ed. Gangliosides and Cancer, VCH Publishers, New York, 1989.

22. Egge, H.; Peter-Katalinic, J. Mass Spectrom. Rev. 1987, 6, 331-393.

23. Mänsson, J.-E.; Friedman, P.; Binger, D.; Molin, K.; Rosengren, B.; Friedman, H. S.; Svennerholm, L. FEBS Letters 1986, $201,109-113$.

24. Levery, S. B.; Nudelman, E. D.; Salyan, M. E. K.; Hakomori, S. Biochemistry 1989, 28, 7772-7781.

25. Peter-Katalinic, J.; Egge, H. In Methods in Enzymology. Vol. 193: McCloskey, J. A., Ed.; Academic Press: Orlando, FL, 1991; pp 713-732.

26. Kushi, Y.; Rokukawa, C.; Handa, S. Anal. Biochem. 1988, 178 $167-176$.

27. Chen, S.; Pieraccini, G.; Moneti, G. Rapid Commun. Mass Spectrom. 1991, 5, 618-621. 
28. Kuei, J.; Her, G.; Reinhold, V. N. Anal. Biochem. 1988, 172, $228-234$.

29. Ohashi, Y.; Wang, R.; Cotter, R.; Fenselau, C.; Nagai, Y. Iyo Masu Kenkyukai Koenshu 1987, 12, 189-192.

30. Furukawa, K.; Chait, B. T.; Lloyd, K. O. I. Biol. Chem. 1988, $263,14939-14947$.

31. Huang, E. C.: Henion, J. D. Proceedings of the 38th ASMS Conference on Mass Spectrometry and Allied Topics; Tucson, AZ, June 2-7, 1990; pp 291-292.

32. Domon, B.; Costello, C. E. Biochemistry 1988, 27, 1534-1543.

33. Ladisch, S.; Sweeley, C. C.; Becker, H.; Gage, D. J. Biol. Chem. 1989, 264, 12097-12105.

34. Kasama, T.; Handa, S. Biochernistry 1991, 30, 5621-5624.

35. Costello, C. E.; Vath, J. E. In Methods in Enzymology, Vol. 193; McCloskey, J. A., Ed.; Academic Press: Orlando, FL, 1991; pp $738-768$.

36. Egge, H.; Peter-Katalinic, J.; Karas, M.; Stahl, B. Pure Appl. Chem. 1991, 63, 491-498.
37. Aduru, S.; Beavis, R. C.; Chait, B. T. Proceedings of the 39th ASMS Conference on Mass Spectrometry and Allied Topics; Nashville, TN, May 19-24, 1991; pp. 935-936.

38. Juhasz, P.; Biller, J. E.; Costello, C. E.; Papayannopoulos, I. A.; Biemann, K. Proceedings of the $39 t h$ ASMS Conference on Mass Spectrometry and Allied Topics; Nashville, TN, May 19-24, 1991; pp. 344-345.

39. Ciucanu, I.; Kerek, F. Carbohydrate Res. 1984, 131, $209-217$.

40. Gunnarsson, A. Glycoconjugate I. 1987, 4, 239-245.

41. Chou, D. K.; Dodd, J.; Jessell, T. M.; Costello, C. E.; Jungalwala, F. B. J. Biol. Chem. 1988, 264, 3409-3415.

42. Svennęrolm, L. I. Neurochem. 1963, 10, 613-623.

43. IUPAC-IUB Commission on Biochemical Nomenclature. Eur. J. Biochem. 1977, 79, 11-21.

44. Beavis, R. C.; Chait, B. T. Rapid Commun. Mass Spectrom. 1989, 3, 432-435.

45. Domon, B,; Costello, C. E. Glycoconjugate J. 1988, 5, 397. 